\title{
New imperssive regulations for the non-fractional order and the time-fractional order of the biological population models
}

\author{
Ahmet Bekir ${ }^{1}$ and Emad Zahran ${ }^{2}$ \\ ${ }^{1}$ Eskisehir \\ ${ }^{2}$ Benha University
}

September 17, 2020

\begin{abstract}
In this article, imperssive exact solutions and hence effective regulations to the non-fractional order and the time-fractional order of the biological population models are achevied for the first time in the framwork of the Paul-Painlevé approach. When the variables appearing in the exact solutions take specific values, the solaitry wave solutions will be easily satisfied.The realized results prove the efficiency of this technique.
\end{abstract}

\section{Hosted file}

MMAS.pdf available at https://authorea.com/users/327788/articles/481580-new-imperssiveregulations-for-the-non-fractional-order-and-the-time-fractional-order-of-thebiological-population-models
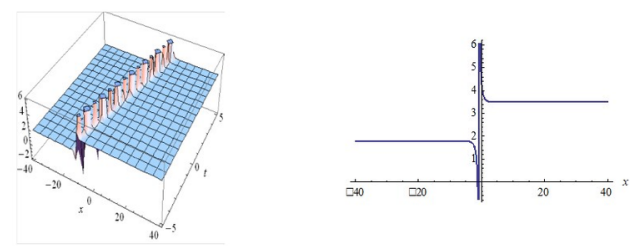

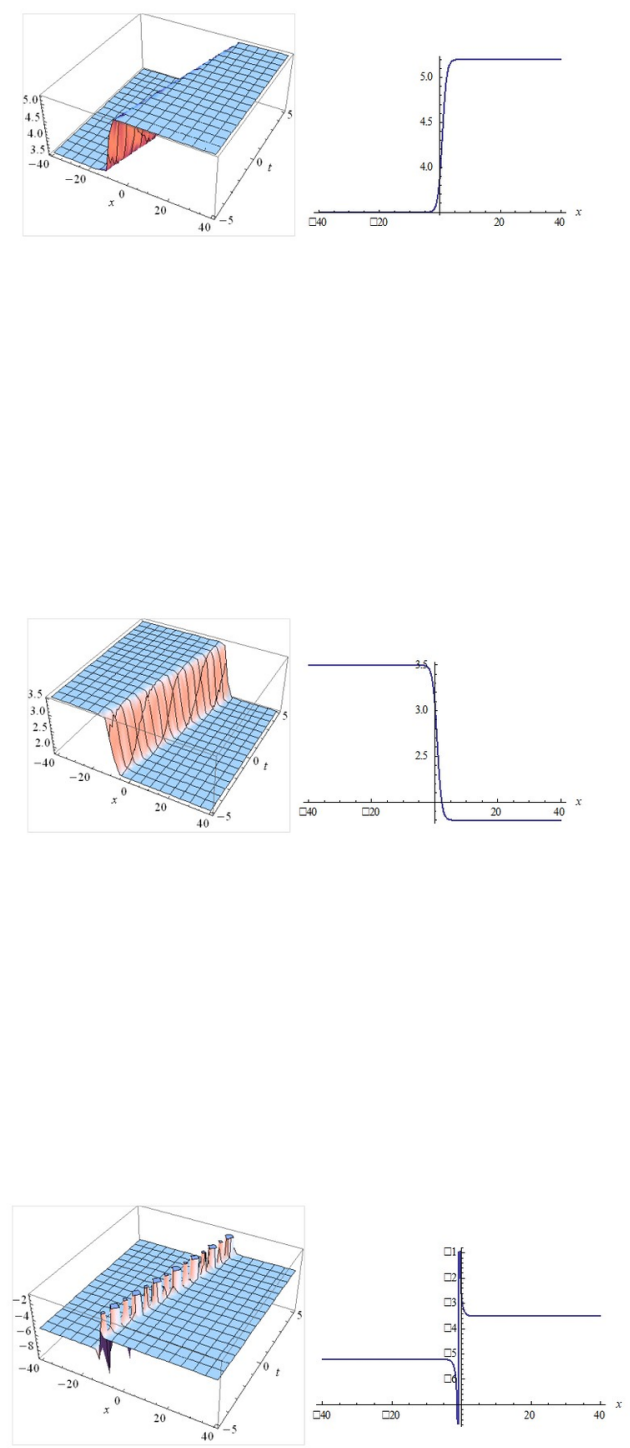

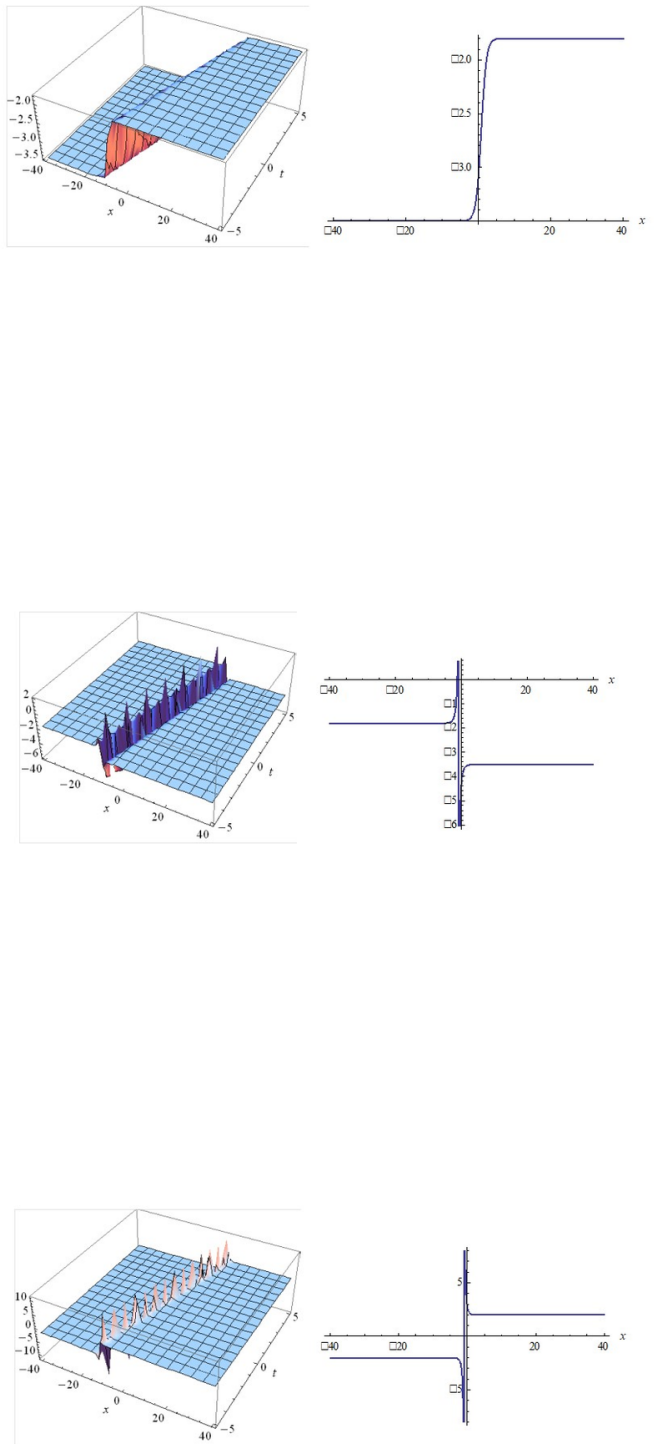

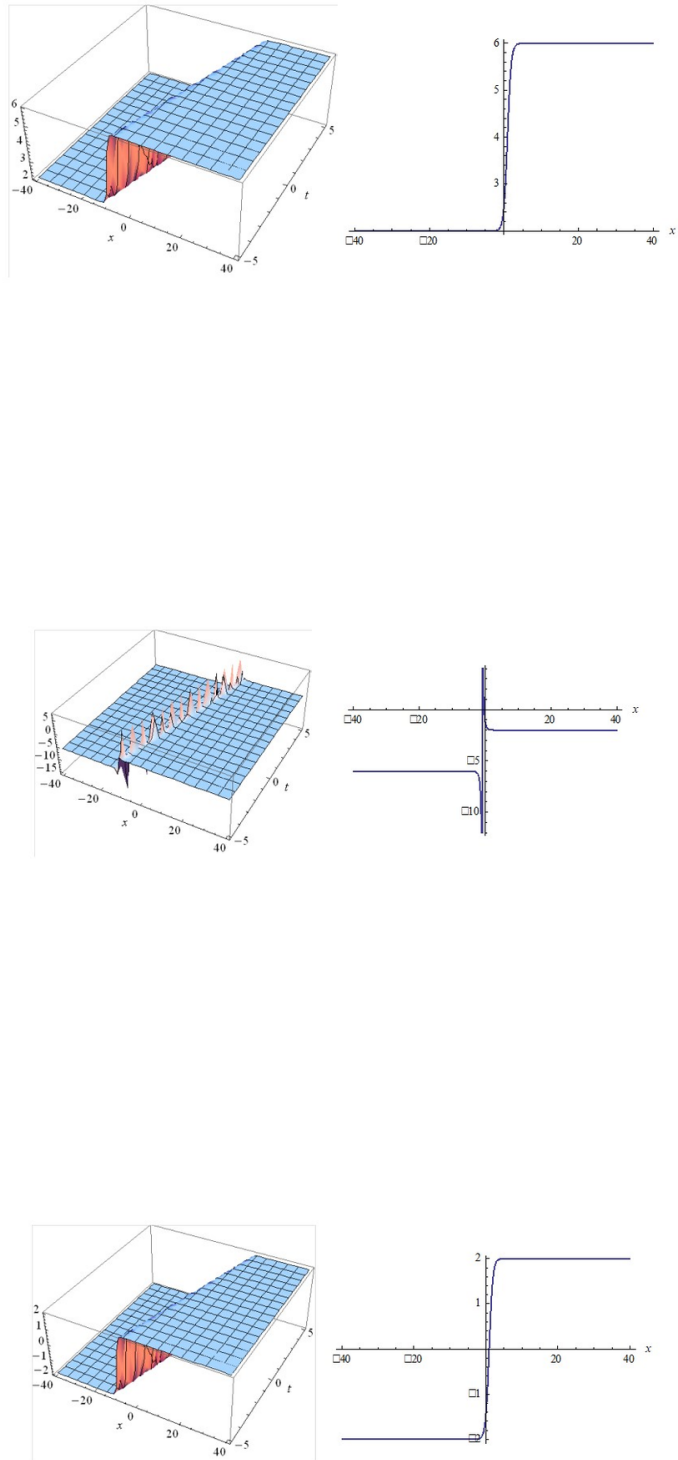